\title{
Three-dimensional power Doppler ultrasound evaluation of placental blood flow in normal monochorionic diamniotic twin pregnancies
}

Wei Sun', Shaowei Yin², Qiuju Wei ${ }^{3}$, Ying Zhang ${ }^{1}$, Zeyu Yang ${ }^{1}$, Ailu Cai ${ }^{1 *}$ D, Yu Wang ${ }^{1}$ and Wenjia Lei ${ }^{1}$

\begin{abstract}
Background: Monochorionic diamniotic (MCDA) twin pregnancies are at higher risk of adverse outcomes and complications, which are attributed to the influence of placental morphology in MCDA twins. Monitoring of placental function is an important index for clinical decisions. The aim of our study was to evaluate the placental blood flow estimated using three-dimensional power Doppler (3D-PD) ultrasound and the vascular indices distribution with gestational age (GA) in normal MCDA twin pregnancies.

Methods: One hundred four MCDA twin pregnancies and 106 singleton pregnancies (GA range, 14-32 weeks) were included in this prospective study. 3D-PD volume data of each fetus was obtained separately from the placenta at the site of umbilical cord insertion. We analyzed the volume data using sonobiopsy technique. The placental vascularization index (VI), flow index (FI) and vascularizationflow index (VFI), were auto-calculated. The means and standard deviation values of three vascular indices per fetus were calculated and regression analysis of the vascular indices as a function of GA was performed in twin pregnancies. The vascular indices of twin and singleton pregnancies were compared using independent $t$-test.

Results: There were no significant differences in VI, FI or VFI among the fetuses of twins $(p>0.05)$. These vascular indices increased over the course of pregnancy $(p<0.05)$. We obtained the regression equations for the indices as a function of GA in days: $\mathrm{VI}=\exp .(4.369-28.533 / \mathrm{GA})\left(R^{2}=0.699, p<0.05\right), \mathrm{FI}=\exp .(3.916-13.003 / \mathrm{GA})\left(R^{2}=0.511, p<\right.$ $0.05)$, and $\mathrm{VFI}=\exp$. (3.577-37.468/GA) $\left(R^{2}=0.675, p<0.05\right)$. There were no significant differences in three vascular indices between MCDA twin and singleton groups ( $p>0.05)$.

Conclusions: 3D-PD placental data using sonobiopsy technique could reflect the placental blood flow of each twin, which could be applied to the study of placental perfusion in MCDA twin pregnancies. This study also presented the vascular indices distribution with GA in normal twin pregnancies, which might be useful for early detection of MCDA complications.
\end{abstract}

Keywords: Monochorionic, Three-dimensional power Doppler, Twin, Prenatal ultrasound, Placenta

\footnotetext{
* Correspondence: caiailu1224@126.com

'Department of Sonography, Shengjing Hospital of China Medical University,

Shenyang, China

Full list of author information is available at the end of the article
}

(c) The Author(s). 2018 Open Access This article is distributed under the terms of the Creative Commons Attribution 4.0 International License (http://creativecommons.org/licenses/by/4.0/), which permits unrestricted use, distribution, and reproduction in any medium, provided you give appropriate credit to the original author(s) and the source, provide a link to the Creative Commons license, and indicate if changes were made. The Creative Commons Public Domain Dedication waiver (http://creativecommons.org/publicdomain/zero/1.0/) applies to the data made available in this article, unless otherwise stated. 


\section{Background}

Monochorionic diamniotic (MCDA) twin pregnancies are at higher risk of adverse outcomes than single or dichorionic diamniotic twin pregnancies, which are attributed to the influence of placental morphology in MCDA twins [1]. The complications of MCDA twin pregnancies include twin-to-twin transfusion syndrome, selective intrauterine growth restriction, twin anemia polycythemia sequence and intra-uterine demise due to uneven blood flow across placental inter-twin vascular anastomoses and/or unequal placental share [2]. Therefore, MCDA twin pregnancies need more monitoring for early detection of complications.

The placenta is an important organ to maintain pregnancy. Monitoring of placental function is an important index for clinical decisions [3]. A number of Doppler studies of placental circulation in normal and pathological pregnancies have been performed. Due to the low velocity of blood flow in the placental vascular villi, conventional color Doppler may lose some blood flow signals to reflect the placental internal perfusion. The pathological basis of abnormal blood flow in umbilical artery is the reduction of the number of placental villi. Reduction of placental blood perfusion comes earlier than the umbilical resistance index. Three-dimensional power Doppler (3D-PD) ultrasound has been used to monitor the placental perfusion, which is not affected by the angle of ultrasound detection or blood flow velocity [4]. 3D-PD, which displays vascular patterns and Doppler signals within tissues, provides estimates of three vascular indices: vascularization index (VI), flow index (FI), and vascularizationflow index (VFI) $[5,6]$.

3D-PD has been widely used in quantitative assessment of fetal/placental blood perfusion of singleton pregnancies [7-11], with little information in twin pregnancies due to the complexity of the placenta. In our study, we prospectively acquired the volume data of twin pregnancies using sonobiopsy technique and evaluate the vascular indices distribution with gestational age (GA), then we compared the vascular indices with those of singleton pregnancies to show the effectiveness of 3D-PD ultrasound in evaluation of placental blood flow in MCDA twin pregnancies.

\section{Methods}

MCDA twin pregnancies (GA range, 14-32 weeks) were included in this prospective study in Shengjing hospital from August 2015 to February 2018. Chorionicity was based on first-trimester ultrasound findings and confirmed by postpartum placental pathology. GA was confirmed by last menstruation and early pregnancy ultrasound examination. Exclusion criteria were as follows: unclear display of umbilical cord insertion site; placenta previa; velamentous cord insertion; the distance between the umbilical cord insertions $\leq 5 \mathrm{~cm}$; fetal malformations or complications; fetal abdominal circumference and/or estimated fetal weight below the tenth percentile for GA; pregnant women with obvious abnormalities or hereditary diseases. The MCDA twins that meet the criteria were included in our study. The twin pregnancies were divided into 19 subgroups according to GA; each group included 5-7 cases. Accordingly, we collected the similar number of singleton fetuses in each GA. A control group was selected from low-risk singleton pregnancies attending our hospital between gestational weeks 14 and 32 for routine ultrasound scan. After delivery, only cases with uneventful pregnancy course were considered for comparison.

This study was approved by the hospital ethics committee. All individual participants included in the study signed the informed consent. All fetuses were followed up and confirmed to be normal after birth. And the placentae of twin pregnancies were confirmed MCDA.

\section{Ultrasound examination}

The Voluson E8 4D ultrasound system (GE Healthcare Austria GmbH \& Co., Pfaffing, Austria) with a 4.08.0 $\mathrm{MHz}$ transabdominal transducer was used for sonographic examinations. An initial two-dimensional conventional study was conducted to obtain general fetal and placental information. At 3D acquisition, the following power Doppler settings were applied to standardize evaluations of placental blood flow: pulse repetition frequency, $0.9 \mathrm{kHz}$; frequency, low; quality, norm; balance, 170; filter, 2; wall motion filter, low-1; smooth, 4/5; artifact, on. Each fetal placental sample was examined in $3 \mathrm{D}$ rendering mode. The power Doppler sampling frame was placed on the connection point between the placenta and umbilical cord. Each gain value was set individually. The sub-noise gain setting was applied to allow the attenuation of power Doppler signal due to different maternal abdominal wall thicknesses and placental sites. At first, the maximum gain value was set and then lowered to a level that could eliminate artifacts and get an accurate image of placental blood vessels [12, 13]. In pregnancies with posterior placentae, the probe was inclined laterally to bring the placenta closer to the probe. The technique adopted a fixed $35^{\circ}$ scanning angle to gather the $3 \mathrm{D}$ volume information close to each fetal umbilical cord insertions. If motion artifacts appeared, acquisition was repeated to obtain clear views of 3D-PD volumes.

The volumes were measured using the virtual organ computer-aided analysis (VOCAL) program (4D View; GE Healthcare Austria $\mathrm{GmbH} \& \mathrm{Co}$ ) by one person. The technique described by Mercé et al. was used for 3D-PD evaluation of the placenta, which was a reproducible and validated method [14-16]. The obtained 3D 
volumes were rotated to locate the area with the highest vascular density. The sphere mode was activated to contain the placental total thickness, while excluding vessels from basal and chorionic plates (Fig. 1). Three indices (range, 0-100) were used for quantitative evaluation of placental blood perfusion of a sphere sample (Fig. 2). VI referred to the percentage of the number of color voxels in the volume of interest. FI referred to the average amplitude values of all color voxels. VFI combined the vessel presence and flow information [6]. The same 3D volume data of each twin was measured three times. The average values of VI, FI and VFI were calculated for each twin.

\section{Data analysis}

The clinical characteristics between MCDA twin and singleton groups were compared using independent $t$-test and Chi-square testing. Difference of three vascular indices between the fetuses of each twin was compared using paired samples $t$-test. Kolmogorov-Smirnov tests were used to confirm the normal distribution of three vascular indices. The means and standard deviation values of three vascular indices per fetus were calculated and regression analysis of the vascular indices as a function of GA was performed in twin pregnancies. The vascular indices of two groups were compared using independent $t$-test. We performed a test-retest series to assess the intraobserver and interobserver variation in measurements. Thirty MCDA twins were examined in duplicate by the same examiner and re-examined by a second examiner. All examiners were blinded to all previous results. All data processing was performed with

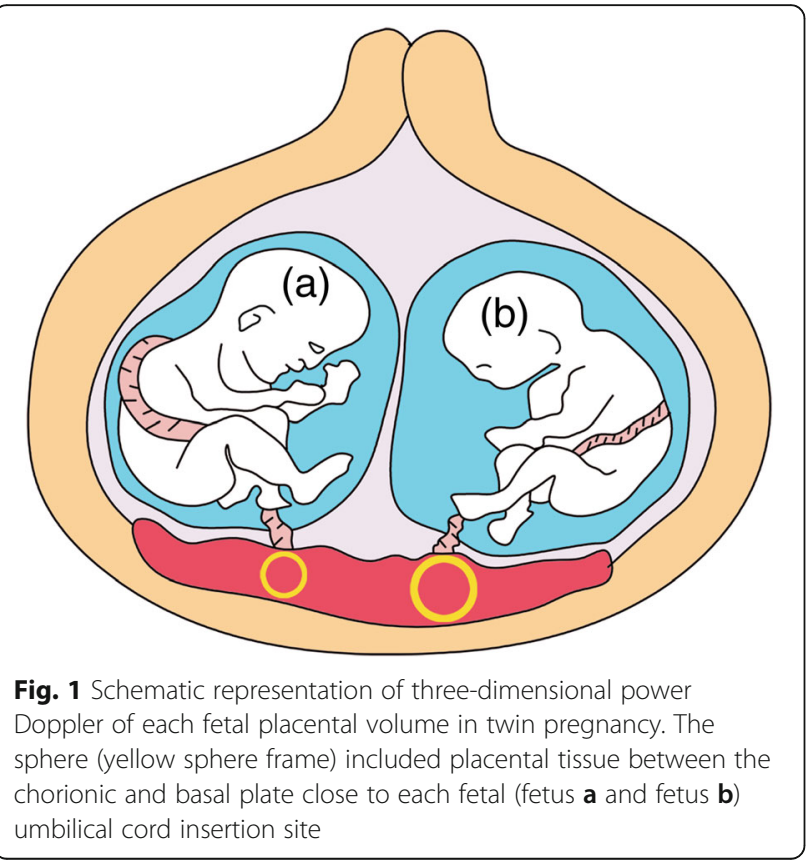

SPSS 23.0 statistical software (SPSS, Inc., Chicago, IL, USA). $P<0.05$ was considered statistical significance.

\section{Results}

A total of 121 MCDA twin pregnancies and 119 singleton pregnancies (GA range, 14-32 weeks) were included in the study. The volume acquisition of 17 twins and 13 singleton fetuses was unsuccessful because of fetal shadowing or frequent fetal movement. The acquisition was successful in 86\% (104/121) / 89\% (106/119) of twin/ singleton pregnancies.

There were no significant differences in maternal age, parity and BMI between the two groups $(p>0.05)$. Table 1 presented the comparative characteristics of subjects between the MCDA twin and singleton groups. There were no significant differences in VFI, FI, and VI between the fetuses of normal MCDA twins $(p>0.05)$. The vascular indices, VI, FI and VFI were plotted as a function of GA on a curve. The scatterplots revealed a positive relationship between the three indices and GA. The regression equations for three indices as a function of GA in days were as follows: $\mathrm{VI}=$ exp. (4.369-28.533/ GA) $\left(R^{2}=0.699, p<0.05\right), \mathrm{FI}=\exp .(3.916-13.003 / \mathrm{GA})$ $\left(R^{2}=0.511, p<0.05\right)$, and VFI $=\exp .(3.577-37.468 / \mathrm{GA})$ $\left(R^{2}=0.675, p<0.05\right)$ (Fig. 3). Table 2 listed the mean values and standard deviations of the three vascular indices of MCDA fetuses by GA from week 14 to 32 . There were no significant differences in three vascular indices between MCDA twin and singleton groups $(p>0.05)$. Line charts displayed the comparisons of vascular values between two groups (Fig. 4).

Intra-observer variations for measurements of placental VI, FI and VFI were 5.7, 15.5 and 9.1\%, respectively, and inter-observer variations were $7.9,17.8$ and $8.1 \%$, respectively.

\section{Discussion}

MCDA twins required more attention for early detection of complications. The placental 3D-PD indices acquired by sonobiopsy technique could reflect the placental blood flow of each twin in MCDA twin pregnancies. Our study provided reference ranges for the placental indices VI, FI, VFI in MCDA twins between gestational weeks 14 and 32, measured using 3D-PD combined with VOCAL.

Many previous reports on measurement of placental blood flow focused on singleton pregnancies. Our study showed the vascular indices increased as pregnancy progressed, consistent with some of them [14, 17]. Some scholars reported different results, due to different analytical methods. De Paula et al. analyzed the vascular indices by 3D-PD scanning the whole placental volume and presented consistent distributions throughout gestational period [16]. This method was more suitable for 

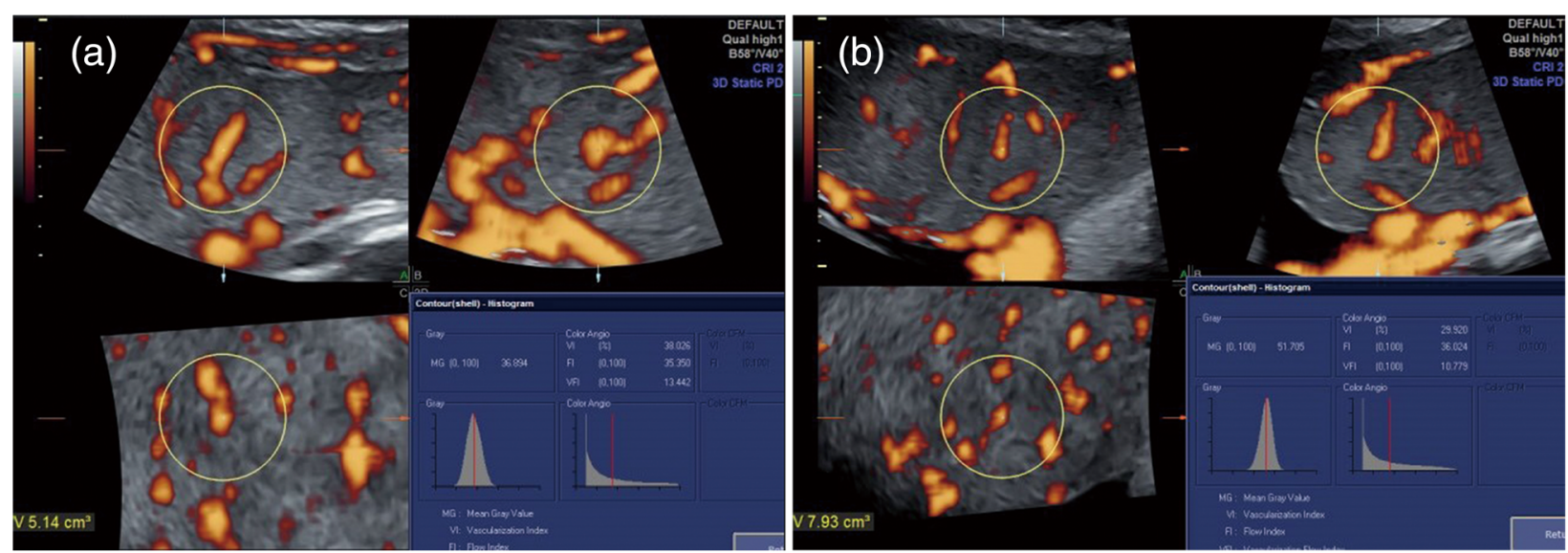

Fig. 2 Acquisition of placental volumes with three-dimensional power Doppler in twin pregnancy. The volume data was acquired close to the umbilical cord implantation site of a normal monochorionic diamniotic twin pregnancy (fetus a and fetus $\mathbf{b}$ ) at gestational week $32^{+6}$. The sphere volume (yellow sphere frame) varied according to placental thickness. Placental indices of fetus a: volume $5.14 \mathrm{~cm}^{3} ; \mathrm{VI} 38.026$; FI 35.35 ; VFI 13.442. Placental indices of fetus $\mathbf{b}$ : volume $7.93 \mathrm{~cm}^{3}$; VI 29.92; FI 36.024; VFI 10.779. FI, Flow index; VFI, Vascularizationflow index; VI,

Vascularization index

study of small placentae, such as early pregnancies $[18$, 19]. MCDA twins shared one placenta; it was difficult to distinguish the placental part of each twin. It was uneasy to scan the whole placental volume in late pregnancy with fetal shadowing. However, it was feasible to catch the site of the umbilical cord insertions of each twin. In our study, we acquired the 3D-PD placental data with Mercés sonobiopsy at the site of each fetal umbilical cord insertion [13]. This method could be used throughout the gestational period. There were no significant differences in VI, FI and VFI of fetuses among MCDA twin and singleton pregnancies. 3D-PD placental data using sonobiopsy technique could reflect the placental blood flow of each twin, which could be applied to the study of placental perfusion in MCDA twin pregnancies.

All MCDA placentae had inter-twin anastomoses. Three principal types of these anastomoses existed, including arteriovenous anastomoses (AVAs), arterioarterial anastomoses (AAAs) and venovenous anastomoses (VVVs). AAAs and VVVs connections were superficial without interposed villous vascular trees. During volume acquisition, we

Table 1 Comparative characteristic of subjects between the MCDA twin and singleton groups

\begin{tabular}{lll}
\hline & $\begin{array}{l}\text { MCDA twin group } \\
(n=104)\end{array}$ & $\begin{array}{l}\text { Singleton group } \\
(n=106)\end{array}$ \\
\hline Maternal age (years old) & $29.2 \pm 6.2$ & $27.7 \pm 3.4$ \\
Parity (primapara/multipara) & $\begin{array}{l}61(58.7 \%) / 43 \\
(41.3 \%)\end{array}$ & $\begin{array}{l}56(53.3 \%) / 50 \\
(46.7 \%)\end{array}$ \\
BMI & $29.9 \pm 4.3$ & $27.6 \pm 4.0$ \\
$\begin{array}{l}\text { Gestational age at time } \\
\text { of delivery (weeks) }\end{array}$ & $35 \pm 3.4^{\mathrm{a}}$ & $38 \pm 2.2$ \\
\hline
\end{tabular}

$B M I$ body mass index, $M C D A$ monochorionic diamniotic, ${ }^{a}, p<0.05$, data were presented compared with the singleton group excluded the blood vessels from basal and chorionic plates. Thus, AAAs and VVVs connections had no effect on the results. AVAs ended in a shared cotyledon and existed in the vascular equator between the twins, often far from the umbilical cord insertion site. The sample volume varied according to placental thickness. In this study, placental thickness was less than $5 \mathrm{~cm}$ in all cases. MCDA twins with an umbilical cord entrance distance of less than $5 \mathrm{~cm}$ were excluded to ensure each fetal independent volume measurements.

Some reports emphasized that the application of 3D-PD should consider the impact of depth of measurement due to acoustic attenuation [20-22]. However, in some clinical studies, there were no significant differences in vascular indices based on placental position, despite the expected attenuation $[6,23,24]$. The signal loss due to attenuation by depth might be compensated by the false Doppler signal generated by the time gain control setting [25]. However, we could not calculate the amount of difference between loss of signal with attenuation and false Doppler signal. There were 18 twin pregnancies with posterior placentae, 7 twin pregnancies with fundal wall placentae in our research. These 25 twin pregnancies had a good visualization of each fetal umbilical cord insertion. We applied some methods to reduce the impact of depth. The probe was inclined laterally to bring the placenta closer to the probe. Individual adjustments of PD were applied for adequate assessment of placental blood flow [12, 13, 25]. From the third trimester on, it was hard to display the umbilical cord insertion sites of MCDA twins in fundal wall or posterior placentae. Therefore, in the third trimester, only the MCDA twins with anterior placentae were enrolled in the study. 

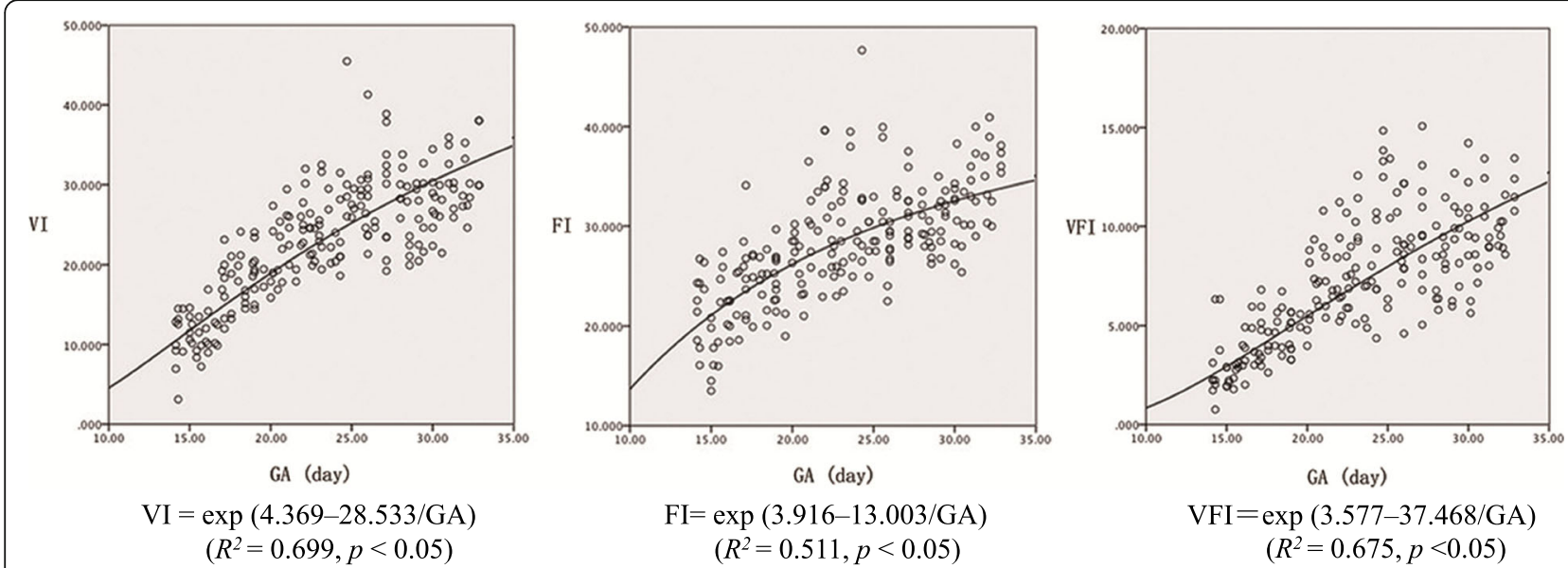

Fig. 3 Scatterplots of vascularization index, flow index and vascularizationflow index versus gestational age. Curve regression lines indicate the mean values. $\mathrm{VI}=\exp .(4.369-28.533 / \mathrm{GA})\left(R^{2}=0.699, p<0.05\right) ; \mathrm{FI}=\exp .(3.916-13.003 / \mathrm{GA})\left(R^{2}=0.511, p<0.05\right) ; \mathrm{VFI}=\exp .(3.577-37.468 / \mathrm{GA})\left(R^{2}=\right.$ $0.675, p<0.05)$. GA, Gestational age; FI, Flow index; VFI, Vascularizationflow index; VI, Vascularization index

3D-PD could display intra-placental vascular tree and quantitatively assessment of placental blood flow [14], which could not be done by 2D Doppler. The vascular indices obtained by sonobiopsy technique showed good intraclass and interclass correlation in our study. It was easy to master the 3D-PD acquisition method. Data post-analysis required time and expertise. However, time would be shortened as experience increased. Therefore, the 3D-PD technique could be applied to traditional ultrasound for monitoring placental blood perfusion in twin pregnancies.

There were some limitations to this study. It was hard to display the umbilical cord insertion sites at an older GA because of the shadowing of twins and crowed

Table 2 Sonographic measurements of placental indices of monochorionic diamniotic twins by gestational age

\begin{tabular}{|c|c|c|c|c|c|c|c|c|c|c|}
\hline \multirow{2}{*}{$\begin{array}{l}\text { GA } \\
\text { (week) }\end{array}$} & \multirow{2}{*}{$\begin{array}{l}\text { Number } \\
\text { of } \\
\text { fetuses }\end{array}$} & \multicolumn{3}{|l|}{$\mathrm{Vl}$} & \multicolumn{3}{|l|}{$\mathrm{FI}$} & \multicolumn{3}{|l|}{ VFI } \\
\hline & & $M$ & $-\mathrm{SD} \sim+\mathrm{SD}$ & $-2 \mathrm{SD} \sim+2 \mathrm{SD}$ & $M$ & $-\mathrm{SD} \sim+\mathrm{SD}$ & $-2 S D \sim+2 S D$ & $M$ & $-\mathrm{SD} \sim+\mathrm{SD}$ & $-2 S D \sim+2 S D$ \\
\hline $14 \sim$ & 10 & 10.6 & $7-14.2$ & $3.4-17.8$ & 22.2 & $18.5-25.9$ & $14.8-29.6$ & 3.1 & $1.2-5$ & $-0.7-6.9$ \\
\hline $15 \sim$ & 12 & 11.1 & $8.9-13.3$ & $6.7-15.5$ & 19.8 & $15.2-24.4$ & $10.6-29$ & 2.5 & $2-3$ & $1.5-3.5$ \\
\hline $16 \sim$ & 10 & 11.8 & $9.4-14.2$ & $7-16.6$ & 21.7 & $19.2-24.2$ & $16.7-26.7$ & 3.9 & $2.7-5.1$ & $1.5-6.3$ \\
\hline $17 \sim$ & 12 & 17.2 & $13.7-20.7$ & $10.2-24.2$ & 25.4 & $21.5-29.3$ & $17.6-33.2$ & 4.2 & $2.9-5.5$ & $1.6-6.8$ \\
\hline $18 \sim$ & 10 & 18.4 & $15.4-21.4$ & $12.4-24.4$ & 24.2 & $21.8-26.6$ & $19.4-29$ & 4.9 & $3.9-5.9$ & $2.9-6.9$ \\
\hline $19 \sim$ & 10 & 18.9 & $15.7-22.1$ & $12.5-25.3$ & 24.2 & $20.9-27.5$ & $17.6-30.8$ & 4.6 & $3.6-5.6$ & $2.6-6.6$ \\
\hline $20 \sim$ & 12 & 20.7 & $17-24.2$ & $13.3-28.1$ & 26.3 & $23.4-29.2$ & $20.5-32.1$ & 6.7 & $5.1-8.3$ & $3.5-9.9$ \\
\hline $21 \sim$ & 10 & 23.4 & $19.8-27$ & $16.2-30.6$ & 29.4 & $25.3-33.5$ & $21.2-37.6$ & 7.5 & $5.9-9.1$ & $4.3-10.7$ \\
\hline $22 \sim$ & 14 & 24.6 & $21-28.2$ & $17.4-31.8$ & 30.6 & $25.4-35.8$ & $20.2-41$ & 7.6 & $5.7-9.5$ & $3.8-11.4$ \\
\hline $23 \sim$ & 12 & 25.1 & $20.8-29.4$ & $16.5-33.7$ & 30.3 & $25-35.6$ & $19.7-40.9$ & 8.1 & $5.6-10.6$ & $3.1-13.1$ \\
\hline $24 \sim$ & 12 & 26.5 & $19.2-33.8$ & $11.9-41.1$ & 31 & $25.2-36.8$ & $19.4-42.6$ & 9.8 & $6.5-13.1$ & $3.2-16.4$ \\
\hline $25 \sim$ & 10 & 27.7 & $25.9-29.5$ & $24.1-31.3$ & 30.5 & $24.8-36.2$ & $19.1-41.9$ & 9.2 & $6.8-11.6$ & $4.4-14$ \\
\hline $26 \sim$ & 10 & 28 & $22.2-33.8$ & $16.4-39.6$ & 29.4 & $27-31.8$ & $24.6-34.2$ & 9 & $6.8-11.2$ & $4.6-13.4$ \\
\hline $27 \sim$ & 10 & 29.1 & $22-36.2$ & $14.9-43.3$ & 31.6 & $28.5-34.7$ & $25.4-37.8$ & 9.8 & $6.8-12.8$ & $3.8-15.8$ \\
\hline $28 \sim$ & 12 & 26.9 & $22.5-31.3$ & $18.1-35.7$ & 29.4 & $27.3-31.5$ & $25.2-33.6$ & 8.2 & $6.5-9.9$ & $4.8-11.6$ \\
\hline $29 \sim$ & 10 & 26.5 & $22.3-30.7$ & $18.1-34.9$ & 31.2 & $28.8-33.6$ & $26.4-36$ & 9.1 & $6.9-11.3$ & $4.7-13.5$ \\
\hline $30 \sim$ & 12 & 27.3 & $23.7-30.9$ & $20.1-34.5$ & 31.1 & $27.3-34.9$ & $23.5-38.7$ & 9.2 & $6.7-11.7$ & $4.2-14.2$ \\
\hline $31 \sim$ & 10 & 30.2 & $26.8-33.6$ & $23.4-37$ & 34.4 & $31-37.8$ & $27.6-41.2$ & 10.2 & $8.5-11.9$ & $6.8-13.6$ \\
\hline $32 \sim$ & 10 & 31.5 & $27-36$ & $22.5-40.5$ & 35.3 & $31.6-39$ & $27.9-42.7$ & 10.7 & $9.2-12.2$ & $7.7-13.7$ \\
\hline
\end{tabular}



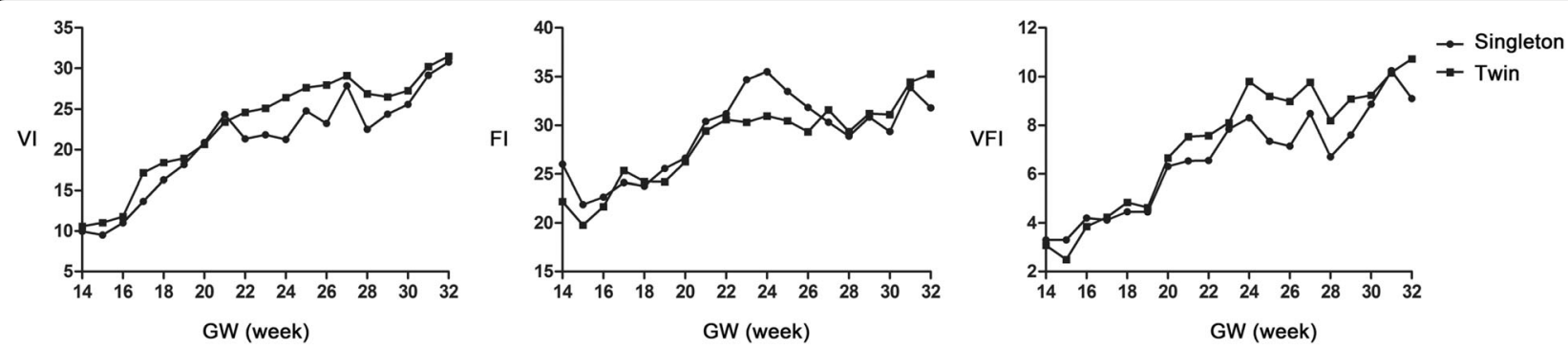

Fig. 4 Comparisons of vascularization index, flow index and vascularizationflow index between twin and singleton pregnancies. Dots represented the mean values at each GA of singleton pregnancies. Squares represented the mean values at each GA of monochorionic diamniotic twin pregnancies. There were no significant differences of VI, Fl, and VFI between MCDA twin and singleton pregnancies $(p>0.05)$. GW, Gestational week; FI, Flow index; VFI, Vascularizationflow index; VI, Vascularization index

space. We didn't get a certain amount of volume data beyond 32 weeks of gestation. Nevertheless, complications of MCDA twin pregnancies mostly occured between 15 and 26 weeks of gestation [2]. There were some limitations in the study of changes of 3D-PD placental indices in the third trimester of MCDA twin pregnancies, thus further studies with larger cohorts of women in late pregnancy were needed to confirm these results. There were 25 twin pregnancies with posterior or fundal wall placentae in our research. To some extent, the inclusion of twin pregnancies with posterior or fundal wall placentae made the result about the changes in VI, FI and VFI before GA 28 might be inaccurate due to depth attenuation.

\section{Conclusions}

3D-PD placental data using sonobiopsy technique could reflect the placental blood flow of each twin, which could be applied to the study of placental perfusion in MCDA twin pregnancies. This study also presented the vascular indices distribution with GA in normal twin pregnancies, which might be useful for early detection of MCDA complications.

\section{Abbreviations}

3D-PD: Three-Dimensional Power Doppler; AAAs: Arterioarterial Anastomoses; AVAs: Arteriovenous Anastomoses; Fl: Flow Index; GA: Gestational Age; MCDA: Monochorionic Diamniotic; VFI: Vascularizationflow Index;

VI: Vascularization Index; VOCAL: Virtual Organ Computer-Aided Analysis; Ws: Venovenous Anastomoses

\section{Acknowledgements}

We thank for all the medical specialists who helped collecting the experimental data. We gratefully acknowledge Prof. Weidong Ren and Prof. Limei Xie for their constructive comments on the design and results of our study.

\section{Funding}

We would like to thank Outstanding Scientific Fund of Shengjing Hospital of China Medical University (No. 201209) for funding this study in the collection of data.

\section{Availability of data and materials}

The datasets used and/or analysed during the current study are available from the corresponding author on reasonable request.

\section{Authors' contributions}

WS, AIC designed the study. WS, SwY, YZ, ZyY collected the data. WS, QjW, AIC, YW, WjL performed the data analyses. YZ, ZyY, AIC, QjW revised the article critically. All authors read and approved the final manuscript.

Ethics approval and consent to participate

Our study has been approved by the ethics committee of Shengjing Hospital of China Medical University (No. 2015PS235K). All women who participated in this study gave written consents.

\section{Consent for publication}

Not applicable.

\section{Competing interests}

The authors declare that they have no competing interests.

\section{Publisher's Note}

Springer Nature remains neutral with regard to jurisdictional claims in published maps and institutional affiliations.

\section{Author details}

${ }^{1}$ Department of Sonography, Shengjing Hospital of China Medical University, Shenyang, China. ${ }^{2}$ Department of Obstetrics and Gynecology, Shengjing Hospital of China Medical University, Shenyang, China. ${ }^{3}$ Department of Obstetrics and Gynecology, the University of Tennessee Health Science Center, Memphis, TN, USA.

Received: 7 August 2018 Accepted: 31 October 2018

Published online: 14 November 2018

\section{References}

1. Akkermans J, Peeters SH, Klumper FJ, Lopriore E, Middeldorp JM, Oepkes D. Twenty-five years of Fetoscopic laser coagulation in twin-twin transfusion syndrome: a systematic review. Fetal Diagn Ther. 2015;38(4):241-53.

2. Benoit RM, Baschat AA. Twin-to-twin transfusion syndrome: prenatal diagnosis and treatment. Am J Perinatol. 2014;31(7):583-94.

3. Taguchi T, Ishii K, Hayashi S, Mabuchi A, Murata M, Mitsuda N. Clinical features and prenatal risk factors for hypertensive disorders in twin pregnancies. J Obstet Gynaecol Res. 2014;40(6):1584-91.

4. Sciaky-Tamir Y, Cohen SM, Hochner-Celnikier D, Valsky DV, Messing B, Yagel S. Three-dimensional power Doppler (3DPD) ultrasound in the diagnosis and follow-up of fetal vascular anomalies. Am J Obstet Gynecol. 2006;194(1): 274-81.

5. Raine-Fenning $\mathrm{N}$. The role of three-dimensional ultrasound in assisted reproduction treatment. Ultrasound Obstet Gynecol. 2004;23(4):317-22.

6. Guimaraes Filho HA, Araujo Junior E, Mattar R, Da Costa LL, de Mello Junior CF, Nardozza LM, Moron AF. Placental blood flow measured by threedimensional power Doppler ultrasound at 26 to 35 weeks gestation in normal pregnancies. J Matern Fetal Neonatal Med. 2010;23(1):69-73.

7. Collins SL, Stevenson GN, Al-Khan A, Illsley NP, Impey L, Pappas L, Zamudio S. Three-dimensional power Doppler ultrasonography for diagnosing 
abnormally invasive placenta and quantifying the risk. Obstet Gynecol. 2015; 126(3):645-53.

8. Mansour GM, El-Mekkawi SF, Akl SA, Abd El Khalek SY. Three-dimensional power Doppler indices of preeclamptic placentas correlated to umbilical artery Doppler and albuminuria. J Matern Fetal Neonatal Med. 2015;28(2): 149-52.

9. Suranyi A, Kozinszky Z, Molnar A, Nyari T, Bito T, Pal A. Placental threedimensional power Doppler indices in mid-pregnancy and late pregnancy complicated by gestational diabetes mellitus. Prenat Diagn. 2013;33(10): 952-8.

10. Noguchi J, Hata K, Tanaka H, Hata T. Placental vascular sonobiopsy using three-dimensional power Doppler ultrasound in normal and growth restricted fetuses. Placenta. 2009;30(5):391-7.

11. Sato M, Noguchi J, Mashima M, Tanaka H, Hata T. 3D power Doppler ultrasound assessment of placental perfusion during uterine contraction in labor. Placenta. 2016:45:32-6.

12. Collins SL, Stevenson GN, Noble JA, Impey L, Welsh AW. Influence of power Doppler gain setting on virtual organ computer-aided AnaLysis indices in vivo: can use of the individual sub-noise gain level optimize information? Ultrasound Obstet Gynecol. 2012;40(1):75-80.

13. Pomorski M, Zimmer M, Florjanski J, Michniewicz J, Wiatrowski A, Fuchs T, Milnerowicz-Nabzdyk E. Comparative analysis of placental vasculature and placental volume in normal and IUGR pregnancies with the use of threedimensional power Doppler. Arch Gynecol Obstet. 2012;285(2):331-7.

14. Merce LT, Barco MJ, Bau S, Kupesic S, Kurjak A. Assessment of placental vascularization by three-dimensional power Doppler "vascular biopsy" in normal pregnancies. Croat Med J. 2005;46(5):765-71.

15. Tuuli MG, Houser M, Odibo L, Huster K, Macones GA, Odibo AO. Validation of placental vascular sonobiopsy for obtaining representative placental vascular indices by three-dimensional power Doppler ultrasonography. Placenta. 2010;31(3):192-6.

16. de Paula CF, Ruano R, Campos JA, Zugaib M. Quantitative analysis of placental vasculature by three-dimensional power Doppler ultrasonography in normal pregnancies from 12 to 40 weeks of gestation. Placenta. 2009; 30(2):142-8.

17. Yu CH, Chang $\mathrm{CH}$, Ko HC, Chen WC, Chang FM. Assessment of placental fractional moving blood volume using quantitative three-dimensional power doppler ultrasound. Ultrasound Med Biol. 2003;29(1):19-23.

18. Demers S, Girard M, Roberge S, Tetu A, Giguere Y, Forest JC, Bujold E. Firsttrimester placental and myometrial blood perfusion measured by threedimensional power Doppler in preeclampsia. Am J Perinatol. 2015;32(10): 920-6.

19. Rizzo G, Capponi A, Pietrolucci ME, Aiello E, Arduini D. First trimester placental volume and three dimensional power doppler ultrasonography in type I diabetic pregnancies. Prenat Diagn. 2012;32(5):480-4.

20. Noguchi J, Tanaka H, Koyanagi A, Miyake K, Hata T. Three-dimensional power Doppler indices at 18-22 weeks' gestation for prediction of fetal growth restriction or pregnancy-induced hypertension. Arch Gynecol Obstet. 2015;292(1):75-9.

21. Jones NW, Hutchinson ES, Brownbill P. Crocker IP, Eccles D, Bugg GJ, RaineFenning NJ. In vitro dual perfusion of human placental lobules as a flow phantom to investigate the relationship between fetoplacental flow and quantitative 3D power doppler angiography. Placenta. 2009;30(2):130-5.

22. Raine-Fenning NJ, Nordin NM, Ramnarine KV, Campbell BK, Clewes JS, Perkins A, Johnson IR. Evaluation of the effect of machine settings on quantitative three-dimensional power Doppler angiography: an in-vitro flow phantom experiment. Ultrasound Obstet Gynecol. 2008:32(4):551-9.

23. Rizzo G, Capponi A, Cavicchioni O, Vendola M, Arduini D. Placental vascularization measured by three-dimensional power Doppler ultrasound at 11 to $13+6$ weeks' gestation in normal and aneuploid fetuses. Ultrasound Obstet Gynecol. 2007:30(3):259-62.

24. Guiot C, Gaglioti P, Oberto M, Piccoli E, Rosato R, Todros T. Is threedimensional power Doppler ultrasound useful in the assessment of placental perfusion in normal and growth-restricted pregnancies? Ultrasound Obstet Gynecol. 2008;31(2):171-6.

25. Martins WP, Raine-Fenning NJ, Ferriani RA, Nastri CO. Quantitative threedimensional power Doppler angiography: a flow-free phantom experiment to evaluate the relationship between color gain, depth and signal artifact. Ultrasound Obstet Gynecol. 2010;35(3):361-8.

Ready to submit your research? Choose BMC and benefit from:

- fast, convenient online submission

- thorough peer review by experienced researchers in your field

- rapid publication on acceptance

- support for research data, including large and complex data types

- gold Open Access which fosters wider collaboration and increased citations

- maximum visibility for your research: over $100 \mathrm{M}$ website views per year

At BMC, research is always in progress.

Learn more biomedcentral.com/submissions 